\title{
Contaminação por hexaclorociclohexanos em área urbana da região Sudeste do Brasil*
}

\author{
Hexaclorociclohexanos contamination in an urban area of South-Eastern Brazil
}

\author{
Rosália M. Oliveira, Ogenis M. Brilhante, Josino C. Moreira, Ary C. Miranda \\ Departamento de Saneamento e Saúde Ambiental da Escola Nacional de Saúde Pública - \\ Brasil (R.M.O., O.M.B.) \\ Centro de Estudos da Saúde do Trabalhador e Ecologia Humana da Escola Nacional de \\ Saúde Pública - Brasil (J.C.M., A.C.M.)
}

\begin{abstract}
Uma fábrica para a produçấo do pesticida hexaclorociclohexano $(\mathrm{HCH})$ técnico (mlstura dos isômeros $\alpha, \beta, \gamma \theta \sigma\}$, pertencente ao antlgo Instituto de Malariologia, entāo Ministério da Educação e Saúde, localizada na Cidade dos Meninos, Duque de Caxias, RJ, foi desativada em 1955. Parte da sua produçăo e de seus rejeitos, em muitas toneladas desta mistura, foram abondonadas no local. A açáo dos ventos e chuvas, assim como a movimentação de aproximadamente mil pessoas, incluindo cerca de 400 crianças que lá residem, provocaram a disseminaçāo deste agente. Amostras de sangue coletadas em moradores da área mostraram níveis de contaminaçð㐅o humana pelo isómero B elevados. As maiores concentraçoes (isômero B) foram encontradas nas pessoas vivendo dentro de um raio de $100 \mathrm{~m}$ em torno dos escombros da fábrica. Amostras de solo e de pasto do local, coletadas em distâncias inferiores a 100 m das rúinas da antiga fábrica, apresentaram concentraçðes dos isómeros do HCH de milhares de $\mathrm{ppb}$, evidenciando alta poluiçăo ambiental.
\end{abstract}

Poluiçdo ambiental. Hexacloreto de benzeno. Residuos de praguicidas, efeitos adversos.

\section{Introduçāo}

O hexaclorociclohexano $(\mathrm{HCH})$, errônea e popularmente denominado $\mathrm{BHC}$, quando não purificado (grau técnico), consiste de uma mistura de uma série de isômeros em diferentes percentagens. A composiçăo centesimal desta mistura é de $65-70 \%$ para o isômero $\alpha, 7-10 \%$ para o isômero B, $14-15 \%$ para o isômero $\gamma, 7 \%$ para o isômero $\sigma$ e 1 - $2 \%$ para impurezas e subprodutos. Dentre esses compostos, somente 0 isômero $\gamma$ (Lindano) possui propriedades inseticidas.

No homem, esses compostos podem ser identificados no sangue, no plasma, no soro, no tecido adiposo e no leite. No Brasil, o uso geral desse pesticida foi proibido em 1985, ficando o mesmo restrito apenas a campanhas de saúde pública (Portaria do Ministério da Agricultura $n^{\circ} 329$ de 2.9.1985).

Em 1989, após uma denúncia de comercialização ilegal desse pesticida em uma feira livre, no Município de Duque de Caxias, RJ, descobriu-se que o mesmo provinha de uma área denominada Cidade dos Meninos, localizada no citado município. Nessa localidade existia uma fábrica de $\mathrm{HCH}$ técnico pertencente ao Instituto de Malariologia que funcionou de 1950 a 1955, sendo então desativada. Com essa desativação, parte de sua produção e rejeitos foram abandonados no local, sem nenhuma proteçāo, sendo dispersa e posteriomnente utilizada

\footnotetext{
* Baseado na Dissertaçāo de Mestrado, subordinada ao título: "Estudo do contaminaçāo do solo e pasto causada por hexaclorociclohexanos (HCH) no Cidade dos Meninos em Duque de Caxias, RJ", Escola Nacional de Saúde Pública, 1994.

Separatas/Reprints: Rosália M. de Oliveira - Departamento de Saneamento e Saúde Ambiental da Escola Nacional de Saúde Pública/FIOCRUZ - Rua Leopoldo Bulhōes, 1480 - 21041-210 - Manguinhos - Rio de Janeiro, RJ - Brasil - Fax: (02I) 280.8194 Recebido em 29.7.1994. Aprovado em 12.4.1995.
} 
por seus habitantes e invasores. Segundo denúncia dos moradores da área, a estrada que atravessa a região teria sido aterrada com o rejeito do $\mathrm{HCH}$, ali abandonado. De acordo com estimativa do orgão ambiental estadual (FEEMA), cerca de $300 \mathrm{t}$ de $\mathrm{HCH}$ ainda se encontram espalhadas no local até os dias de hoje.

A "Cidade dos Meninos" abrange uma área de $19.000 .000 \mathrm{~m}^{2}$ onde estão localizados abrigos para crianças carentes (Abrigo Cristo Redentor), os quais possuem hoje em dia cerca de 400 intemos, alguns residentes há mais de 10 anos. A população residente, junto com a populaçăo flutuante dessa localidade, incluindo os funcionários dos abrigos, perfazern um contingente de aproximadamente mil indivíduos. Muitas dessas pessoas estão em contato permanente com o pesticida há mais de 30 anos. Culturas de subsistência tais como hortaliças, frutas, legumes (por exemplo o aipim) e criaçōes de animais domésticos (gado de corte e leiteiro) são observadas, inclusive em área de contaminação elevada.

Um levantamento analítico preliminar, realizado em um segmento da populaçâo residente (31 moradores do local), relatado no presente trabalho, revelou elevada contaminação com teores séricos dos diversos isômeros do $\mathrm{HCH}$, até 70 vezes superiores àqueles encontrados em populaçōes nâo expostas.

Têm sido relatados níveis de isômeros de $\mathrm{HCH}$ em solo de várias regið̋es. Em certas áreas da Alemanha foram encontrados níveis de Lindano variando de 1 a $10 \mathrm{ppm}$ em solos não agricultutáveis. Contudo, em algumas áreas agrícolas foram encontradas concentrações de até $600 \mathrm{ppm}$ (Fricke ${ }^{3}, 1972$ ). Na Ucrânia, 36 dentre 136 amostras de solo analisadas apresentaram níveis de Lindano variando entre 100 e $5.000 \mathrm{ppb}$ (Izmerov', 1983 e WHO', 1991).

Estudos com pasto e forragem em geral, utilizados na alimentaçăo de animais, mostraram que estes podiam conter níveis de concentrações importantes de pesticidas organoclorados tais como o HCH e o DDT (Gromova $\left.{ }^{4}, 1990\right)$.

O presente trabalho tern por objetivo relatar os níveis de contaminação superficial do solo e pasto por $\mathrm{HCH}$ da citada regiāo e correlacionar preliminarmente os dados com os encontrados no soro de pessoas e crianças residentes na "Cidade dos Meninos".

\section{Materlal e Método}

\section{- Coleta e Preparação das Amostras}

Na Figura 1 é apresentado o plano geral uti- lizado para a amostragem do solo e pasto do local estudado.

As amostras superficiais de solo, identificadas como P1...P27, foram coletadas a uma profundidade média de $10 \mathrm{~cm}$ em distâncias variando de 15 $\mathrm{m}$ a $2,5 \mathrm{Km}$, das ruínas da antiga fábrica, mencionada anteriormente.

Os métodos de coleta seguiram as normas utilizadas pela Empresa Brasileira de Pesquisa Agropecuária (EMBRAPA², 1979).

O solo controle, apresentando características físicas e químicas semelhantes ao solo da regiảo em questāo, foi coletado nas proximidades da Estrada do Alto da Boa Vista, a cerca de $50 \mathrm{~km}$ do sítio estudado.

Amostras de pasto, identificadas como V1...V5, constituídas de grama do tipo Pernambuco (Paspalum $s p$ ), foram coletadas também de acordo com as citadas normas.

As amostras de solo, depois de coletadas, foram postas para secar sobre papel laminado por 4 dias, à temperatura ambiente, e depois de tamizadas em uma peneira de 20 mesh, o material peneirado foi triturado em gral e guardado em vidro âmbar, especialmente preparado para este fim, e estocado em freezer a $-15^{\circ} \mathrm{C}$.

As amostras de pasto também sofreram o mesmo processo de secagem que as de solo, sendo em seguida acondicionadas e estocadas da mesma forma.

Antes do processo de extração por solventes, essas amostras foram cortadas em pequenos pedaços e pesados.

\section{- Extração por Solvente}

Um grama de solo, previamente seco, foi misturado com $1 \mathrm{~g}$ de sulfato de sódio anidro e submetido à extração em Soxhlet, com aproximadamente $150 \mathrm{ml}$ de $\mathrm{n}$-hexano (grau resíduo de pesticida), por 14 horas, a uma razāo de extraçăo de 6 ciclos (sifonados)/hora.

O extrato obtido foi concentrado a vácuo, em evaporador rotatório (temperatura do banho: $40^{\circ} \mathrm{C}$; pressão: $400 \mathrm{mmHg}$ ), até um volume de aproximadamente $3 \mathrm{ml}$ e posteriormente transferido quantitativamente, com auxilio de pequenas porçōes de n-hexano, para tubo calibrado de $3 \mathrm{ml}$. Em seguida, concentrado a $1 \mathrm{ml}$ em corrente de nitrogênio e, por fim, avolumado a $3 \mathrm{ml}$ com n-hexano.

\section{- Análise Cromatográfica}

Os extratos foram analisados por cromatografia gasosa de alta resolução, usando um 


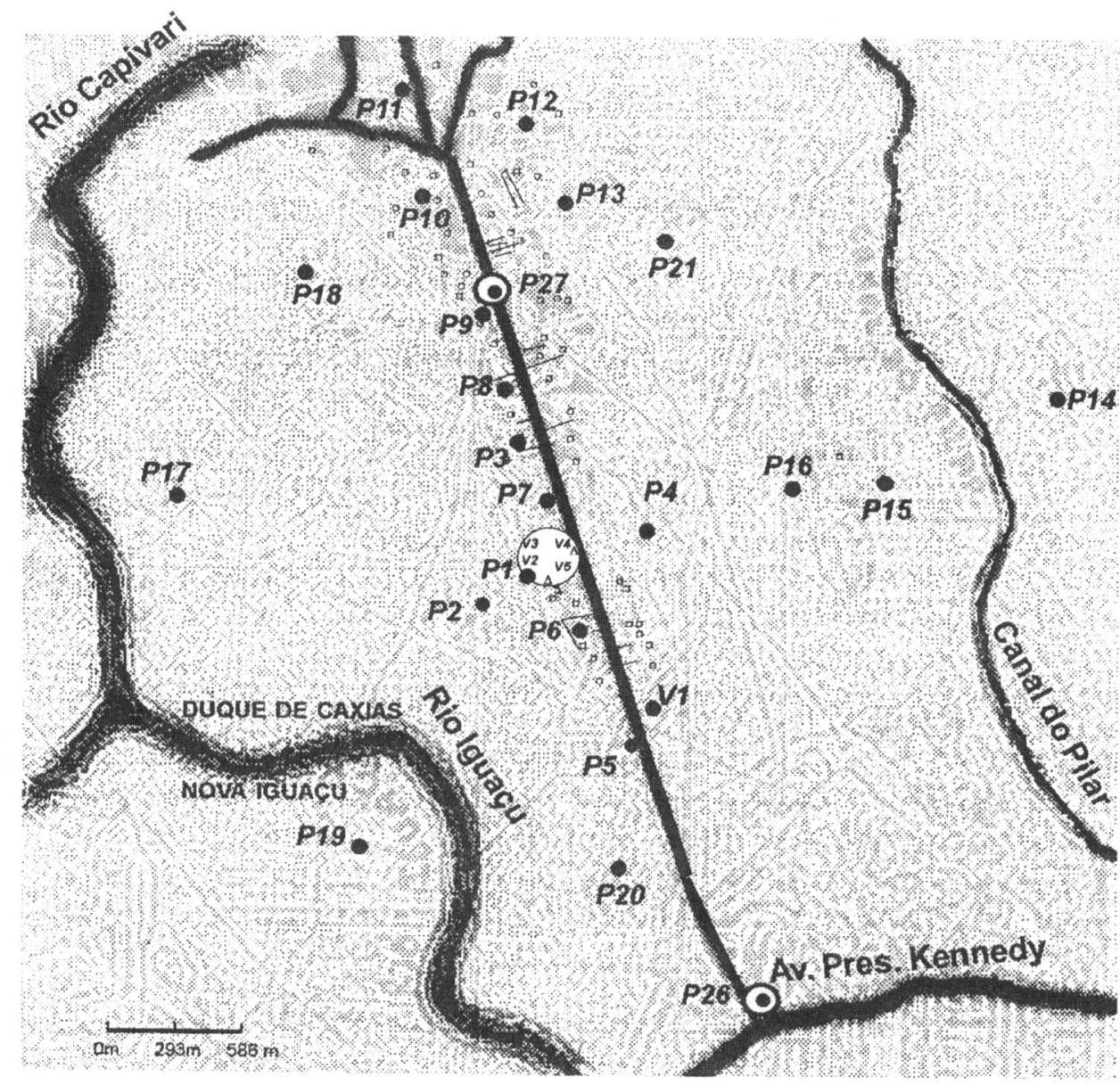

\section{LEGENDA:}

\begin{tabular}{|c|c|}
\hline & Estrada Principal \\
\hline םם & Residências e prédios da administração do abrigo \\
\hline$\Delta \Delta \Delta$ & Redidências localizadas a menos de 100 metros do foco \\
\hline$\vee 1, \ldots, V 5$ & Amostras de gramíneas (pasto) \\
\hline (2) & Focos de contaminação sobre a estrada \\
\hline & Principal foco de contaminação: ruínas da fábrica \\
\hline
\end{tabular}

Flgure 1: Plano de amostragem de solo e pasto na área da Cidade dos Meninos.

detector de captura de elétrons e uma coluna de sílica fundida, fase estacionária HP-5 (5\% fenil/95\% metilpolisiloxano), com $25 \mathrm{~m}$ de comprimento $\times 0,25 \mathrm{~mm}$ de diâmetro interno $\times 0,11$ $\mu \mathrm{m}$ de espessura do filme da fase estacionária. Os seguintes parâmetros foram utilizados na análise cromatográfica: temperatura do forno, $100^{\circ} \mathrm{C}(2$ min) $-8^{\circ} \mathrm{C} / \mathrm{min}-150^{\circ} \mathrm{C}(6 \mathrm{~min})-3^{\circ} \mathrm{C} / \mathrm{min}-160^{\circ} \mathrm{C}$ $-12^{\circ} \mathrm{C} / \mathrm{min}-280^{\circ} \mathrm{C}(10 \mathrm{~min})$; temperatura do injetor, $250^{\circ} \mathrm{C}$; temperatura do detector, $290^{\circ} \mathrm{C}$; gás de arraste, hidrogênio ultra puro a um fluxo de 1 $\mathrm{ml} / \mathrm{min}$; gás de make up do detector, nitrogênio ultra puro a um fluxo de $60 \mathrm{ml} / \mathrm{min}$; volume injetado de $1 \mu 1$ e técnica de injeçāo com divisão de amostra de 1:10.

\section{Resultados}

Os testes de recuperação dos isômeros do $\mathrm{HCH}$ realizados em amostras enriquecidas, com os padrões destes isômeros, mostraram rendimento entre 85 - 90\%, o que é compatível com estudos anteriormente relatados (Sherma $\mathrm{e}$ Beroza $^{6}, 1980$ ).

Análises físicas e químicas realizadas em amostras de solo, nos perfis verticais da região de estudo, mostram que a mesma é dominada por sedimentos de baixada, aluvionais, onde ocorrem classes de solos tipo Cambissolo Plíntico, Glei Húmicos, Podzólicos VermelhoAmarelos e Planossolos. 
$\mathrm{O} \mathrm{pH}$ do solo da Cidade dos Meninos é ácido. variando de 4,6 a 4,8 e a concentração de matéria orgânica encontrada na camada superficial do solo variou de 0,24 a $10,27 \%$, com uma média de $2,8 \%$.

Os teores dos diferentes isômeros do $\mathrm{HCH}$ encontrados nas amostras superficiais de solo são mostrados nas Figuras 2 e 3.

Os resultados obtidos na análise das amostras de pasto, que serve de alimento para o gado da região, são mostrados na Figura 4.

\section{Discussāo}

Os resultados da poluição superficial do solo por $\mathrm{HCH}$, apresentados nas Figuras $2 \mathrm{e} 3$. mostram que para distâncias inferiores a $100 \mathrm{~m}$, medidas a partir das ruínas da fábrica, as concentrações dos isômeros do $\mathrm{HCH}$ sâo muito elevadas; da ordem de milhares de ppb. Para distâncias superiores a $100 \mathrm{~m}$ (Fig. 3) quase todos os pontos apresentam concentrações inferiores a $100 \mathrm{ppb}$.

Dos três pontos que apresentam concentrações dos isômeros maiores que $100 \mathrm{ppb}$, dois estão localizados sobre a estrada principal que atravessa a área (P26 e P27) e um outro situado nas proxjmidades desta mesma estrada, porém em cota inferior (P4). As concentraçôes elevadas, encontradas nos pontos $\mathrm{P} 26$ e $\mathrm{P} 27$. confirmariam as afirmaçōes de moradores da região que material contaminado proveniente da área foco teria sido utilizado na terraplanagem da estrada. $O$ alto teor residual de $\mathrm{HCH}$, encontrado no perfil $\mathrm{P} 4$, pode ser explicado pelo arraste mecânico deste produto através da açāo dos ventos e da chuva. Este último, favorecido pelo fato de estar situado numa cota inferior à da estrada aterrada com material contaminado.

Foi observada extensiva contaminação das amostras de pasto analisadas, com concentraçōes dos isômeros do $\mathrm{HCH}$ da ordem de milbares de ppb. Esses resultados não são surpreendentes uma vez que quatro dessas amostras foram coletadas dentro de um raio de $100 \mathrm{~m}$ das ruínas da antiga fábrica. Elevadas concentraçōes foram também encontradas na amostra V1, coletada a cerca de $1,1 \mathrm{~km}$ das ruínas da antiga fábrica. A proximidade do ponto de coleta desta amostra, com a estrada de terra $(50 \mathrm{~m})$, poderia explicar em parte esta forte contaminação. A grande superfície de contato da gramínea com o solo, uma vez que esta cresce praticamente rente a esse e a topografia plana da região que favorece grande exposição aos ventos, são fatores que podem contribuir para um maior depósito do produto na superfície da folha, ocasionando resultados mais elevados de concentrações de $\mathrm{HCH}$.

Os valores extremamente elevados das concentrações dos isômeros $\sigma$ para a amostra Vl e $\beta$ para a amostra V3 evidenciam um enriquecimento local destes isômeros através de processos ainda não completamente entendidos.

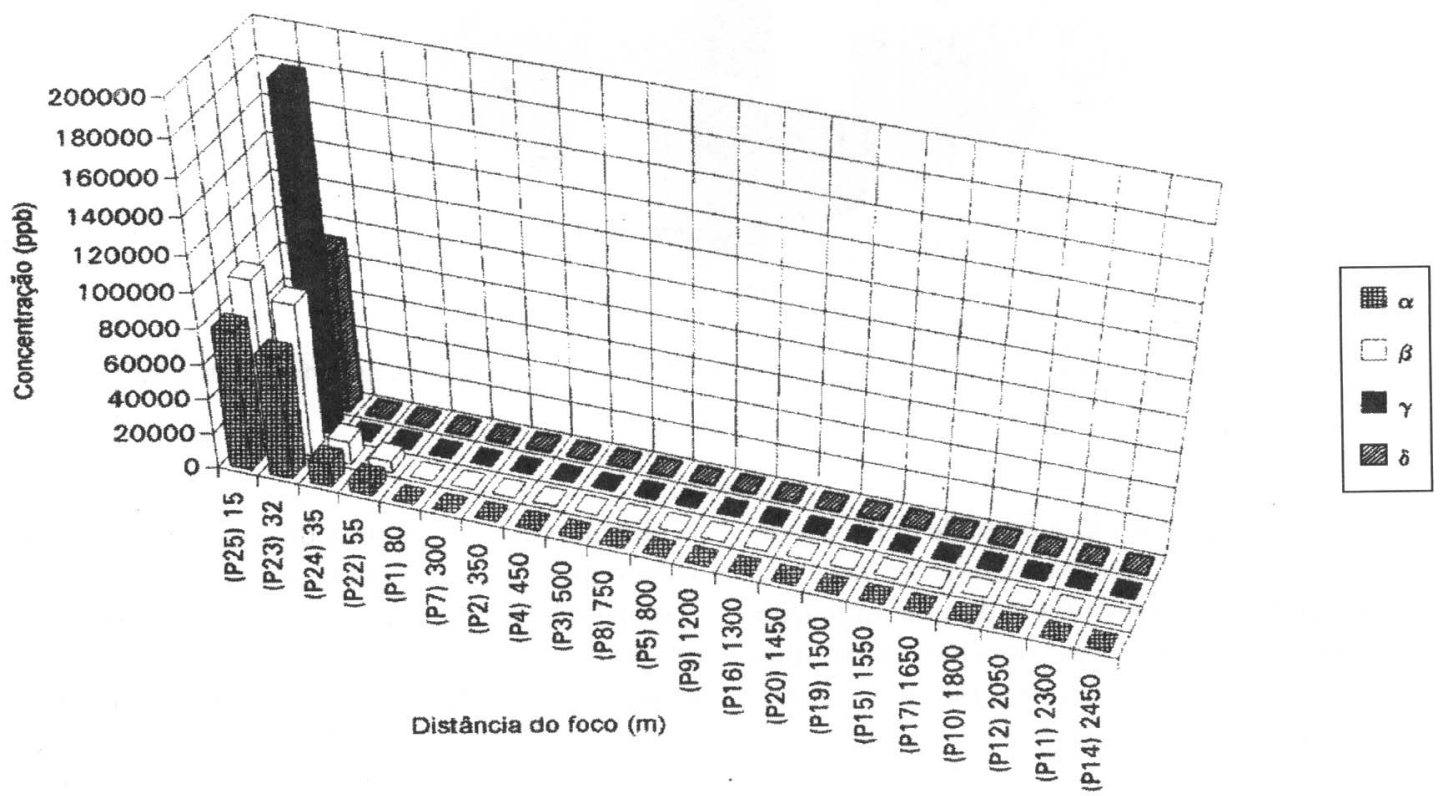

Figura 2 - Concentração dos isômeros do HCH encontradas nas amostras superficiais de solo versus distância do foco. 


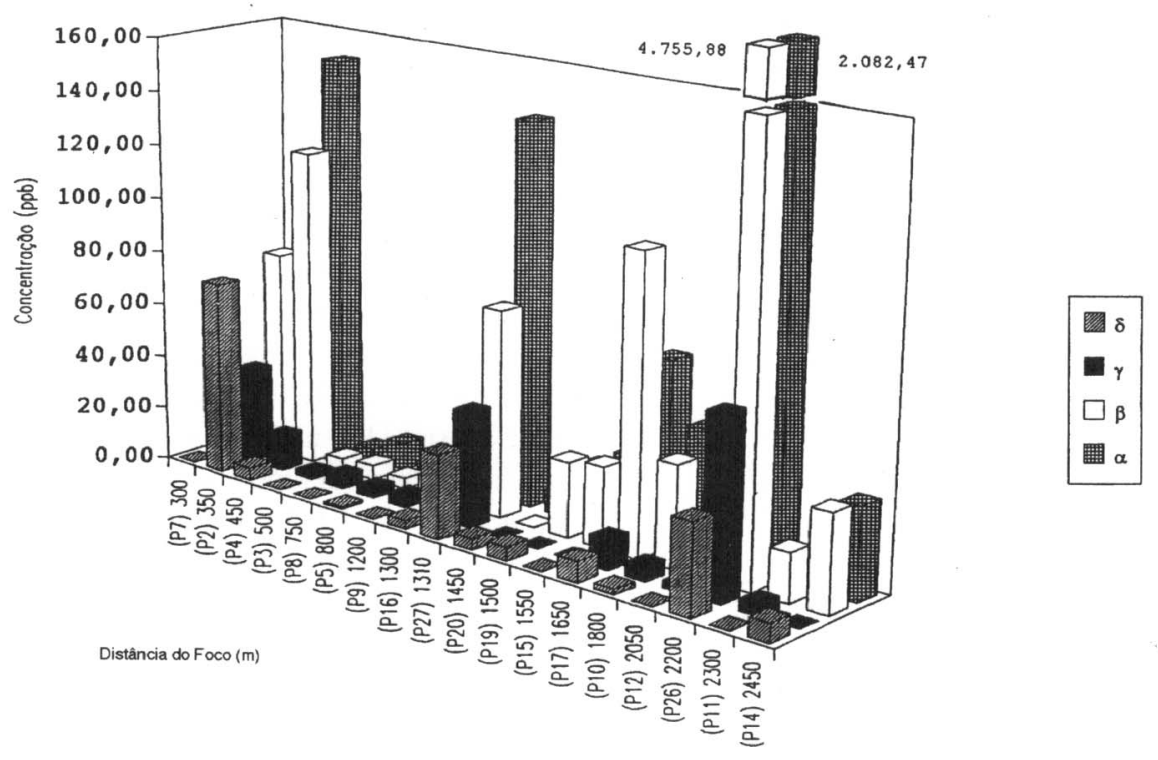

Flgura 3 - Concentraçāo dos isômeros do $\mathrm{HCH}$ encontradas nas amostras superficiais de solo versus distâncias superiores a cem metros do foco.

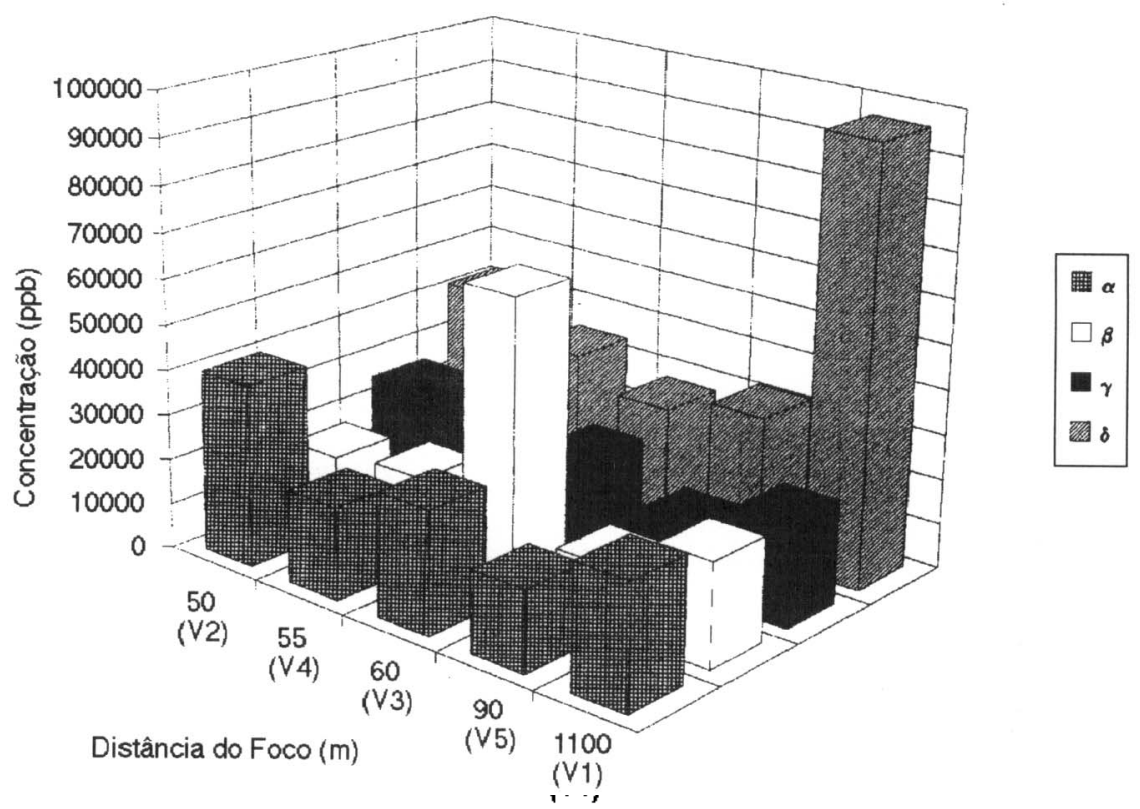

Figura 4 - Concentraçāo dos isômeros do HCH encontradas nas amostras superficiais de solo versus distância do toco.

Os resultados obtidos na análise de amostras de soro sangüíneo de 31 pessoas residentes no local mostram que os maiores níveis de contaminação foram encontrados nas pessoas que vivem nas proximidades das ruínas da antiga fábrica. Embora este estudo nåo tenha conseguido associar estes resultados ao tempo de residência dessas pessoas na área, foi verificado que elas consumiram, sistematicamente, alimentos produzidos no local.
Resultados das análises de soro, realizadas em 186 crianças que residem na área poluída, evidenciaram segundo Braga', a contaminaçăo de cerca de $28 \%$ com relação ao isômero $B$ (mais persistente). Este resultado evidencia, também que $72 \%$ das crianças não apresentaram nenhuma contaminação, embora o solo da área onde vivem apresente concentrações dos isômeros de $\mathrm{HCH}$ da ordem de dezenas de ppb. 


\section{Conclusăo}

$O$ presente trabalho mostrou que embora a poluiçẫo do $\mathrm{HCH}$ tenha se espalhado por uma grande extensão, três micro-áreas distintas podem ser identificadas: a área constituída pelos arredores das ruínas da antiga fábrica, com um raio de 100 $\mathrm{m}$, apresentando concentraç̄es de milhares de $\mathrm{ppb} ; \mathrm{a}$ estrada que atravessa a regiāo de estudo, com concentraçôes de dezenas e centenas de ppb; e a área restante com concentraçóes de algumas dezenas de ppb para os isômeros $\alpha, B$ e $\sigma$ e concentraçס̃es inferiores a $13 \mathrm{ppb}$ para o isômero $\gamma$.

As altas concentrações encontradas para os quatro isômeros do $\mathrm{HCH}$ nas amostras de pasto evidenciam um risco considerável de exposição humana pela cadeia alimentar.

Os resultados obtidos com as análises de soro sanguíneo parecem indicar

que as crianças do grupo de estudo, residentes no Abrigo Cristo Redentor, têm maior probabilidade de exposição ao produto, mas que o risco não e uniforme, apesar do presente trabalho ter demonstrado a presença de isômeros de $\mathrm{HCH}$ em todas as amostras de solo e pasto.

Com base nos presentes resultados pode-se levantar a hipótese de que os $28 \%$ de crianças cujas amostras de sangue apresentaram algum tipo de contaminação poderiam ter sido expostas a partir de contatos mais diretos com as duas áreas de maior poluição, identificadas neste trabalho, ou, ainda, pelo consumo sistemático de alimentos provenientes do local.

As mesmas hipoteses se aplicariam às pessoas do primeiro grupo que apresentaram concentrações de alguns dos isômeros de HCH bastante elevadas.

\section{Agradecimentos}

Aos Doutores Francesco Palmieri e Osório Oscar M. da Fonseca, pesquisadores do Serviço Nacional de Levantamento e Conservação de Solos (SNLCS), EMBRAPA, RJ.

\section{Referências Blbliográficas}

1. BRAGA, A.M.C.B. Relatório das análises de soro de residentes na Cidade dos Meninos. CESTEH/FIOCRUZ, 1990.

2. EMBRAPA. Serviço Nacional de Levantamento e Conservação de Solos. Mantual de métodos de análise de solo. Brasilia, 1979.

3. FRICKE, G. Contamination of soils with chlorinated hydrocatbon insecticides, comparizon of 1969 with 1972 (comunication 1, field vegetable growing). Gesunde Plantz, 24 (11): 177, 1972.

4. GROMOVA, V.S. Various principles of the formation of toxic gaseous pesticide degrada- tion products in the soil. Gig, sanit., 8: 225, 1990 .

5. IZMEROV, N.F., ed. Lindane. Moscow, Centre of International Projects, 1983. (IRPTC Scientific reviews of Soviet literature on toxjcity and hazards of chemicals, $n^{\circ} 40$ ).

6. SHERMA, J. \& BEROZA, M. Manual for analytical quality control for pesticides and related compounds in buman and environmental samples. Otawa, Environmental Protection Agency, 1980.

7. WORLD HEALTH ORGANIZATION. Lindane. Geneve, 1991. (WHO-Environmental Health Criteria, 124).

\begin{abstract}
A factory for producing the pesticide hexachlorocyclohexane (HCR) in its technical grade (mix of the $\alpha, \beta, \gamma$, and $\sigma$ isomers), that belonged to the former institute of Malaria Sciences, then Ministry of Education and Health, located in the "Cidade dos Meninos", county of Duque de Caxias, Stafe of Rio de Janeiro, was closed down in 1955. Part of its production and westes - many tons this $\mathrm{mix}$ - were left behind on the site. The action of winds and rain as well as the movement of the local inhabitants - approximately 1,000 people, including 400 children, have caused the scaltering of this agent. Blood speciments from the inhabitants showed high human contamination levels, with the highest concentrations ( $\beta$ isomers) being found in pelople living within a 100 meter radius of the ruin of the factory. Local soll and pesture samples taken at distances of less than $100 \mathrm{~m}$ from the ruin of the former factory showed HCH isomer concentrations of the order of thousands of ppb, thus providing evidence of high environmental contamination.
\end{abstract}

Environmental pollution. Benzene hexachloride. Pesticide residues, adverse effects. 